\title{
Identifying potential surface water sampling sites for emerging chemical pollutants in Gauteng Province, South Africa
}

\author{
F Petersen', JM Dabrowski² and PBC Forbes ${ }^{3 *}$ \\ 'Department of Geography, Geoinformatics and Meteorology, University of Pretoria, Lynnwood Road, Pretoria, 0002, South Africa \\ ${ }^{2}$ CSIR, Natural Resources and the Environment, PO Box 395, Pretoria, 0001, South Africa \\ ${ }^{3}$ Department of Chemistry, University of Pretoria, Lynnwood Road, Pretoria, 0002, South Africa
}

\begin{abstract}
Emerging chemical pollutants (ECPs) are defined as new chemicals which do not have a regulatory status, but which may have an adverse effect on human health and the environment. The occurrence and concentrations of ECPs in South African water bodies are largely unknown, so monitoring is required in order to determine the potential threat that these ECPs may pose. Relevant surface water sampling sites in the Gauteng Province of South Africa were identified utilising a geographic information system (GIS). The sites were identified by identifying potential sources of ECPs, including hospitals and clinics, sewage treatment plants, and areas with high population densities or areas that were vulnerable from an environmental point of view. Buffers were drawn around these areas to identify the water sources which have the highest probability of containing ECPs. Areas along the Klip River were identified as having a high likelihood of containing both anthropogenic ECPs and agricultural ECPs. Additionally, sections of the Hennops River were likely to contain anthropogenic ECPs, while the Blesbokspruit area had a high likelihood of containing agricultural ECPs.
\end{abstract}

ABSTRACT

\section{INTRODUCTION}

Challenges in terms of water quality and quantity can be expected throughout the $21^{\text {st }}$ century (Jackson, et al. 2005). Science and technology hold many advantages for humanity but their advancement often comes at the cost of the environment. The development of novel chemicals is no exception to this statement as they hold benefits in fields such as agriculture (in the form of pesticides) or human health (in the form of pharmaceuticals). These novel and useful chemicals can have unintended negative effects if they end up in the environment, especially in water resources, after they have fulfilled their initial purpose. When these chemicals enter the natural environment they become known as emerging chemical pollutants (ECPs). Although there is no standardised definition of what exactly an ECP is, Liu et al. (2014) defined an ECP as a novel chemical that does not have a regulatory status, but which can potentially be harmful to human health and the environment. However, ECPs have also been defined to include regulated chemicals such as polychlorinated biphenyls (PCBs), as they can cause endocrine disruption (Diamond et al. 2011).

Aquatic ecosystems are a sink for natural and anthropogenic chemicals (Diamond et al. 2011). Effective monitoring of the aquatic environment is warranted and ECPs are no exception to this statement. However, ECPs are poorly characterised in terms of their presence in water resources and their effects on biota (Diamond et al. 2011). Once they enter the ecosystem, ECPs and their degradates can be transported and distributed between major ecological compartments, based on factors such as: how the ECP was originally released into the environment, its

*To whom all correspondence should be addressed. Tel: +27 12 420-5426; e-mail: patricia.forbes@up.ac.za Received 10 June 2016; accepted in revised form 5 January 2017 degradation rate, its half-life, and partition coefficients (Fent et al. 2006).

The potential threat of contamination posed by ECPs is of specific concern to South Africa as only $8.6 \%$ of the annual rainfall is available as surface water (Haarhoff et al., 2015). There is also a large constituent of South Africa's general population that lives in rural or poorly developed areas with insufficient infrastructure that includes a compromised water value chain (Ncube et al., 2012).

In the past, sampling of ECPs within South African water systems has been limited to areas that are perceived to have high levels of pollution. The majority of the sites that have been sampled typically featured concentrations that were too low to be of any concern (Haarhoff et al. 2015). However, information surrounding ECPs and the contamination they can cause under South African conditions is scarce. The efficacy of the current National Toxicity Monitoring Programme is limited by inadequate sampling sites, analysis and budget (Haarhoff et al., 2015). Recent studies on South African water bodies reported finding ECPs in the Rietvlei Dam, which is one of the largest water bodies in the Gauteng Province (Barnhoorn et al., 2013). Calcified testes of the mammals surrounding Rietvlei Dam as well as intersex fish within the water body itself were also reported. The authors attributed these findings to elevated levels of lindane, DDT and PCBs detected in the fatty tissues of the organisms. All these chemicals are ECPs, suggesting that ECPs may be present in other South African ecosystems and thus the risk they pose should be studied, ascertained and mitigated. A method for identifying optimal sampling sites for ECPs for future research would serve as an invaluable stepping stone towards the detection, evaluation and eventual control of ECPs in South African water bodies.

Sampling all 930 water supply systems (municipalities and water utilities) that exist in South Africa for hazardous chemicals is impractical (Haarhoff et al., 2015). One method for focusing sampling efforts is the use of a geographic information 
system (GIS) for determining high-risk areas based on relevant variables. The most at-risk areas can then be sampled at regular intervals for ECP contamination. This approach was applied for generating risk maps within the province of Gauteng. The resulting maps are useful for performing spatial assessments of human and environmental risks with respect to ECPs, and provide a valuable resource for both researchers in the field of ECPs in South Africa, as well as for regulators and municipalities.

\section{METHODS}

The method was based on locating the river catchment areas within the Gauteng region that would be the most susceptible to contamination. Various procedures were followed in order to locate suitable sampling areas which could possibly contain contaminants in the most vulnerable areas within Gauteng, with a specific focus on anthropogenic chemicals (Fig. 1). Anthropogenic chemicals in this case are all manmade chemicals with the exception of agricultural chemicals. The process began with the identification of all protected and vulnerable areas within each of the catchments according to their ecosystem status as defined by the South African National Biodiversity Institute. The next steps were identifying the number of medical facilities and wastewater treatment works (WWTWs), and determining the population density.

From this information, an analysis was done to determine the most vulnerable catchments, which would experience the most detrimental effects if high levels of contaminants were found. This analysis was completed by overlaying the preceding variables within each catchment. Here, each factor most likely to contribute to contamination within the catchment was analysed according to a criterion and further ranked based on risk. The combinations of variables were then overlaid to extract the catchments most susceptible to contaminants. The rivers within these vulnerable catchments were further extracted and maps depicting the areas which are most vulnerable as well as having a high probability of containing contaminants were created (Fig. 1).

A similar process was followed for agricultural chemicals (Fig. 2). Population density was retained as a parameter: for the anthropogenic chemicals population density meant there was a greater risk of those chemicals finding their way into the water resources of the region as well as increasing the likelihood of the chemical to cause harm as a consequence of increased potential exposure. In the case of the agricultural chemicals population density was directly related to the potential for an agricultural chemical to cause harm.

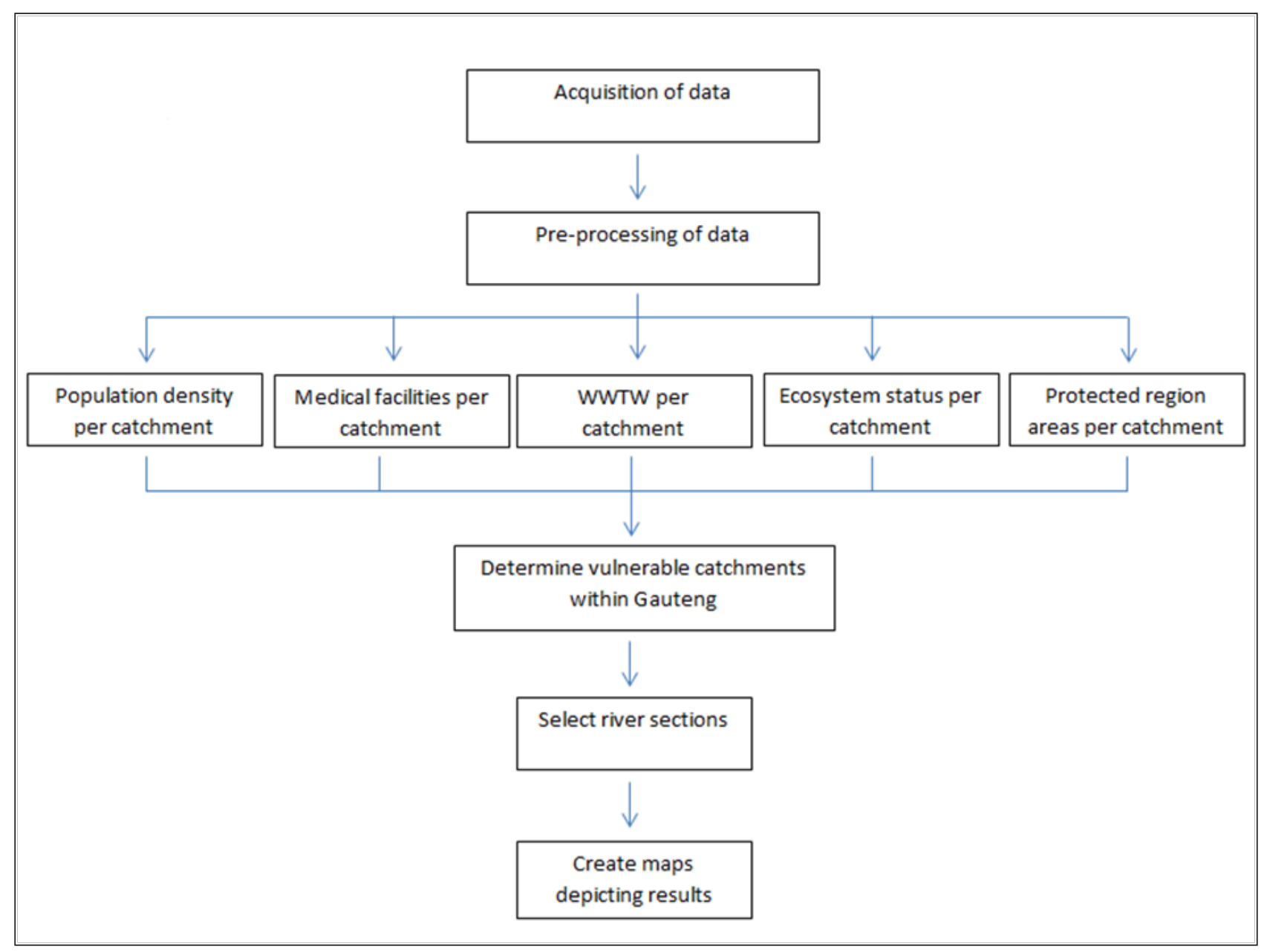

Figure 1

Overview of GIS methodology for determining river sections most vulnerable to anthropogenic substances 


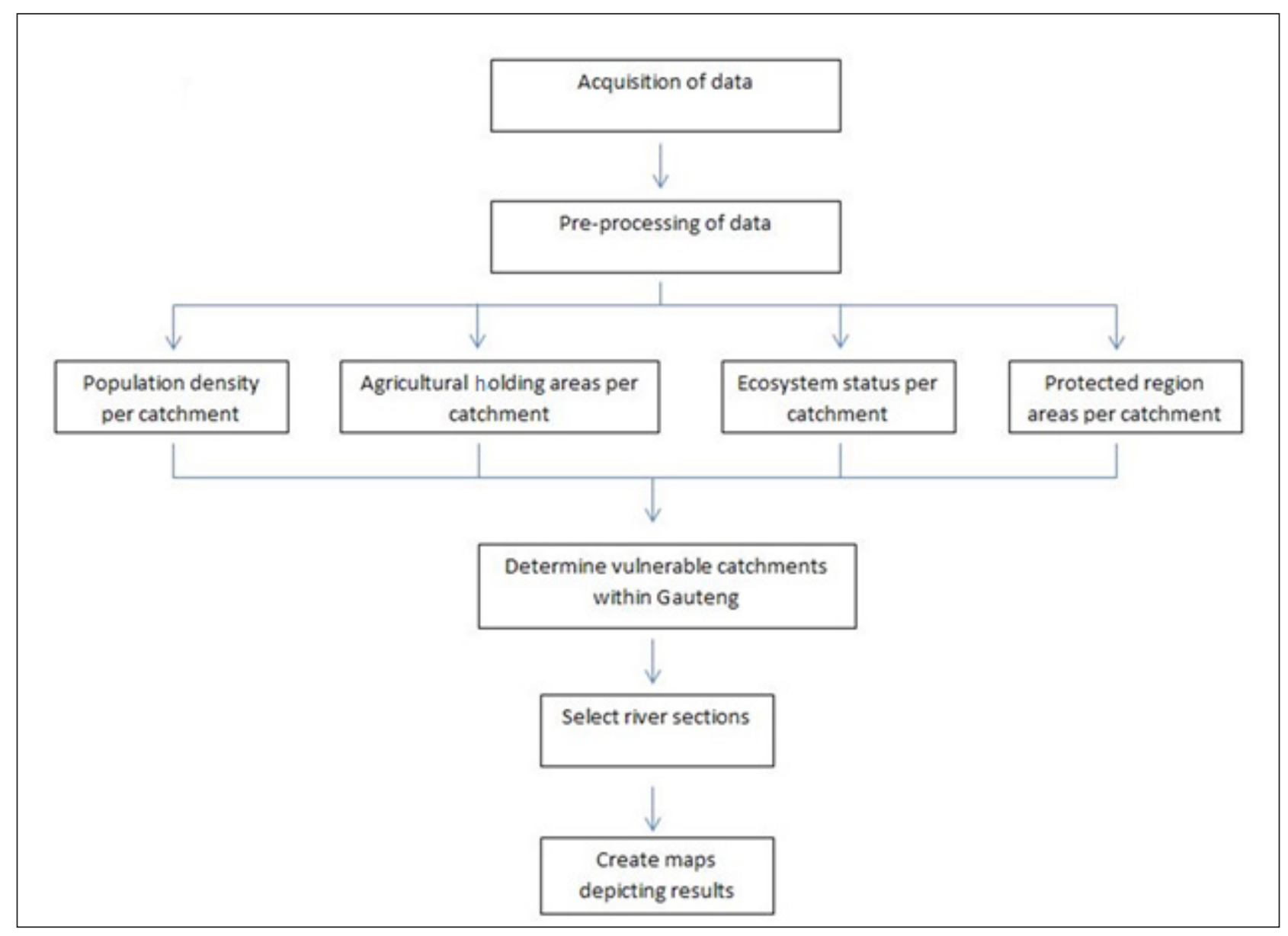

Figure 2

Overview of GIS methodology for determining river sections most vulnerable to agricultural substances

\section{Data collection}

A number of geographical datasets were collated from various sources (Table 1).

\section{Pre-processing of data}

The first step in analysing the data and selecting suitable sampling sites was to ascertain data interoperability between the required datasets. For this project, Environmental Systems Research Institute (ESRI) ArcGIS software package version 10.1 was utilised. The ArcGIS data interoperability Spatial ETL tool facilitates conversions between formats and creates a platform where the data can be analysed and visualised regardless of the format. All datasets acquired for this study were clipped to the Gauteng Province for faster analysis and processing, with the exception of the catchments where all those that overlapped the Gauteng Province boundary were used.

\section{Selecting vulnerable catchment(s) (anthropogenic chemicals)}

The first step was to determine the population density per catchment. The current population density data were available per electoral ward. A geostatistical analysis tool was used to reallocate data from ward polygons to catchments in a two-step process. First, a smooth predication surface was created from the source polygon, in this case the population per ward, and then this surface was reallocated to each of the target catchment polygons, giving a good estimate of population per catchment.

Medical facilities and WWTWs are likely to be sources of contaminants due to the high concentration of ECPs used or processed by them; therefore the second step in selecting the vulnerable catchments was to locate the number of medical facilities and WWTWs per catchment. This was done using a spatial join to count the number of medical facilities and WWTWs per catchment. This layer was then joined with the population density layer calculated in the previous step.

Next, the protected areas and areas of concern per catchment were determined by importing all the protected and high priority areas into ArcGIS, after which the model builder tool was used to clip all the features within each catchment. The protected areas per catchment were subsequently summed in a spreadsheet. A high ratio of total protected area to catchment area means that the vulnerability status of the catchment is high.

Lastly, the ecosystem status of each catchment was established from the South African National Biodiversity Institute (SANBI) dataset which classifies areas according to whether an ecosystem is critically threatened, threatened, vulnerable or least threatened. The attribute containing the status was joined to the catchments dataset. 


\begin{tabular}{|c|c|c|c|}
\hline \multicolumn{4}{|c|}{$\begin{array}{l}\text { TABLE } 1 \\
\text { Required spatial and non-spatial datasets and the sources thereof for GIS modelling (all the data were requested directly } \\
\text { from the source indicated and as such were obtained via personal communication) }\end{array}$} \\
\hline Required dataset & Format & Main purpose & Source \\
\hline Population density & Shapefile per ward & $\begin{array}{l}\text { Used to determine which catchment would } \\
\text { be most vulnerable }\end{array}$ & Statistics South Africa \\
\hline Wastewater treatment works & Excel sheet & $\begin{array}{l}\text { Locate containment points and create risk } \\
\text { weighting }\end{array}$ & $\begin{array}{l}\text { Department of Water and Sanitation, } \\
\text { South Africa }\end{array}$ \\
\hline Medical facilities & Shapefile (points) & $\begin{array}{l}\text { Locate containment points and create risk } \\
\text { weighting }\end{array}$ & Department of Health, South Africa \\
\hline Protected areas & Shapefile (polygons) & $\begin{array}{l}\text { Determine areas of vulnerability and } \\
\text { contribute to the selection of catchments }\end{array}$ & $\begin{array}{l}\text { South African National Biodiversity } \\
\text { Institute }\end{array}$ \\
\hline Water catchments & Shapefile (polygons) & Used as base data & $\begin{array}{l}\text { Department of Water and Sanitation, } \\
\text { South Africa }\end{array}$ \\
\hline Water features & $\begin{array}{l}\text { Shapefile (lines and } \\
\text { polygons) }\end{array}$ & Used as base data and obtain sampling areas & $\begin{array}{l}\text { National Geospatial Information via } \\
\text { MapIT and AfriGIS }\end{array}$ \\
\hline Land-use data & Raster data & Ecosystem status & National Geospatial Information \\
\hline Agricultural data & Shapefile (polygons) & To determine areas of vulnerability & $\begin{array}{l}\text { Department of Agriculture, Forestry and } \\
\text { Fisheries, South Africa }\end{array}$ \\
\hline Orientation data & Various formats & Orientation, visualisation and planning & $\begin{array}{l}\text { South African National Biodiversity } \\
\text { Institute, AfriGIS, National Geospatial } \\
\text { Information }\end{array}$ \\
\hline
\end{tabular}

All variables were now available for identifying the catchments that would potentially be most vulnerable if contaminants were found. Using Structured Query Language (SQL) within ArcGIS software it was possible to select the catchment areas with high population density, high number of potential containment outlets as well as larger vulnerable areas that could be affected. Catchments vulnerable to anthropogenic chemicals from medical facilities and wastewater were those that met the following criteria:

- The catchment population was more than a third of the total population of Gauteng

- The catchment had more than a third of all the medical facilities in Gauteng

- The catchment had more than two WWTWs

- The catchment had a critically threatened ecosystem status

- The total catchment protected area exceeded 1000 ha

River sections that overlapped the vulnerable areas were then extracted using a 'select by location' tool.

\section{Selecting vulnerable catchment(s) (agricultural chemicals)}

The determination of catchments which are vulnerable due to ECPs arising from agricultural holdings followed a similar process. All of the agricultural holdings within Gauteng were obtained from National Department of Agriculture data. The summed areas of agricultural holdings per catchment were then calculated by first joining the agricultural holding layer with the Gauteng catchment by location and then by applying a 'join via attribute' to the original dataset. Catchments vulnerable to anthropogenic chemicals from agricultural holdings were those that met the following criteria:

- The catchment population density fell within the highest category natural break class for Gauteng

- The catchment had an endangered ecosystem status
- The total catchment protected area exceeded 1000 ha

- The total area of agricultural holdings in the catchment was 7000 ha or more

River sections that overlapped the vulnerable areas were then extracted using a 'select by location' tool.

\section{Displaying results}

The spatial data layers were scaled, categorised and symbolised. Each of the variables, together with some orientation data, were employed to create transverse Mercator maps to depict each stage of the methodology together with the final results displaying the vulnerable catchments and river sections.

\section{RESULTS}

The population density of Gauteng catchments ranges from $5000 \mathrm{~km}^{-2}$ to more than $20000 \mathrm{~km}^{-2}$ (Fig. 3). The ecosystem status of most catchments in Gauteng is 'Endangered' or 'Vulnerable' (Fig. 4). There are more protected areas located in the northern parts of Gauteng. This is clear as there are more catchments that have protected areas larger than 1000 ha in size located in the north of Gauteng (Fig. 5). Health facilities in Gauteng are, as one would expect, clustered around the metropolitan areas, with some catchments having more than 100 (Fig. 6). Wastewater treatment plants serve the metropolitan areas, but are downstream of the metropolitan areas (Fig. 7). Areas of agricultural holdings were surprisingly high in periurban areas, exceeding 10000 ha in Soweto (Fig. 8). The most vulnerable catchments for anthropogenic substances, taking all criteria into account, were the Klip River in Soweto and south of Johannesburg, and the Hennops River in the southern part of the City of Tshwane (Fig. 9). The Klip River in Soweto and south of Johannesburg was also one of the most vulnerable for agricultural substances, along with the Springs and Blesbokspruit areas on the East Rand. The sources of the data used in the creation of each of the maps are the same as indicated in Table 1. 


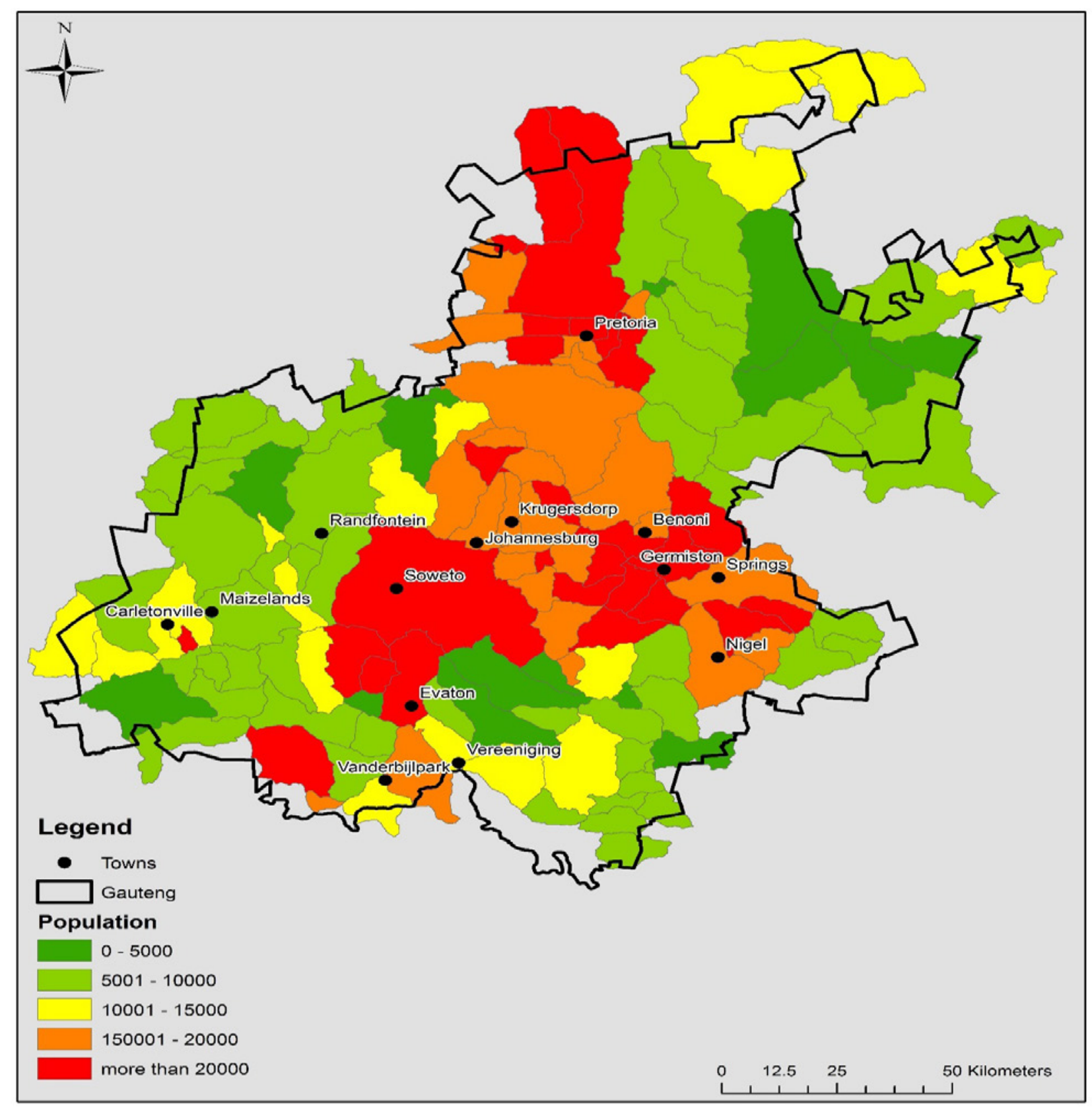

Figure 3

Population density (number of people per $\mathrm{km}^{2}$ ) per catchment in Gauteng 


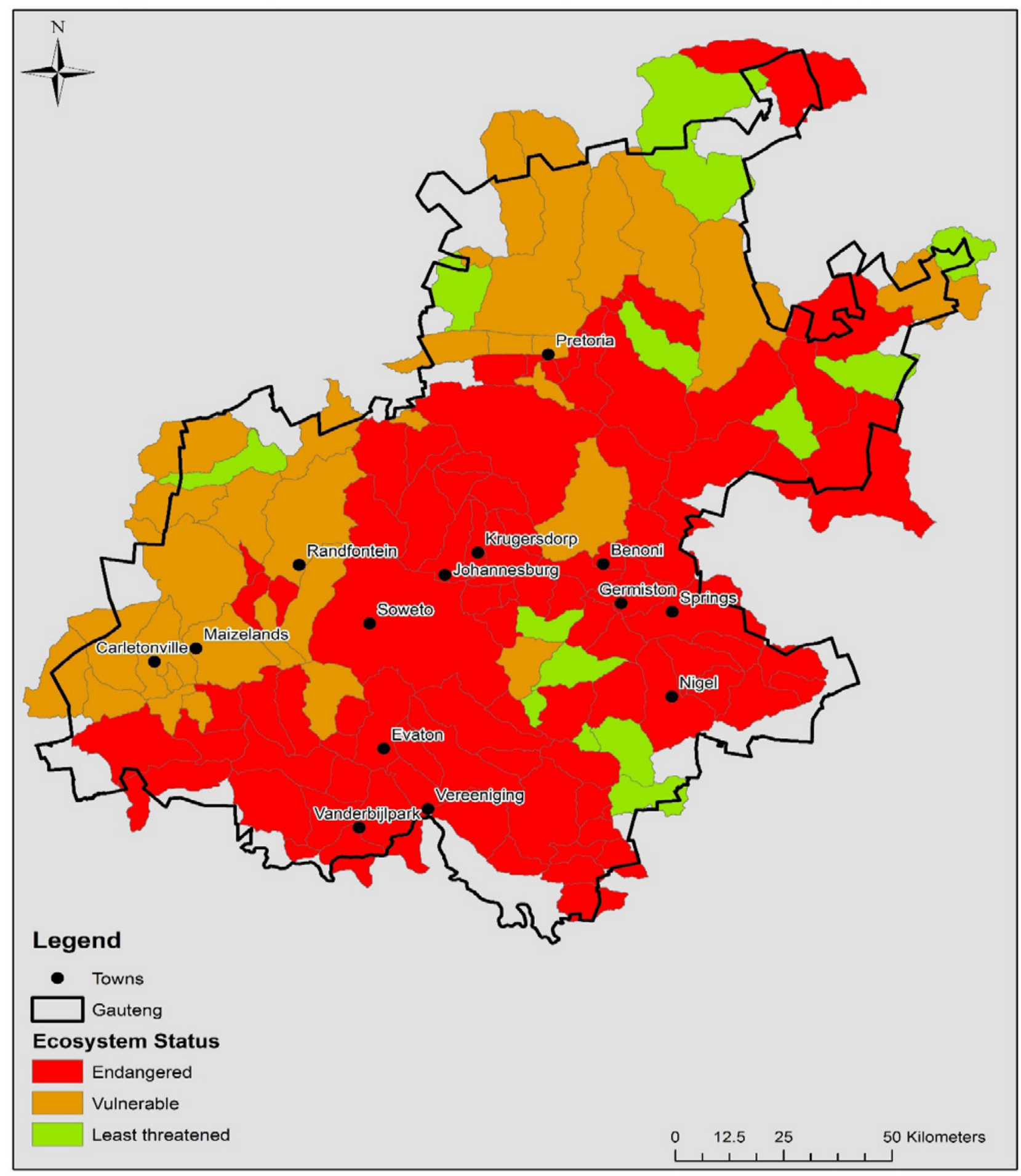

Figure 4

Status of ecosystem per catchment in Gauteng 


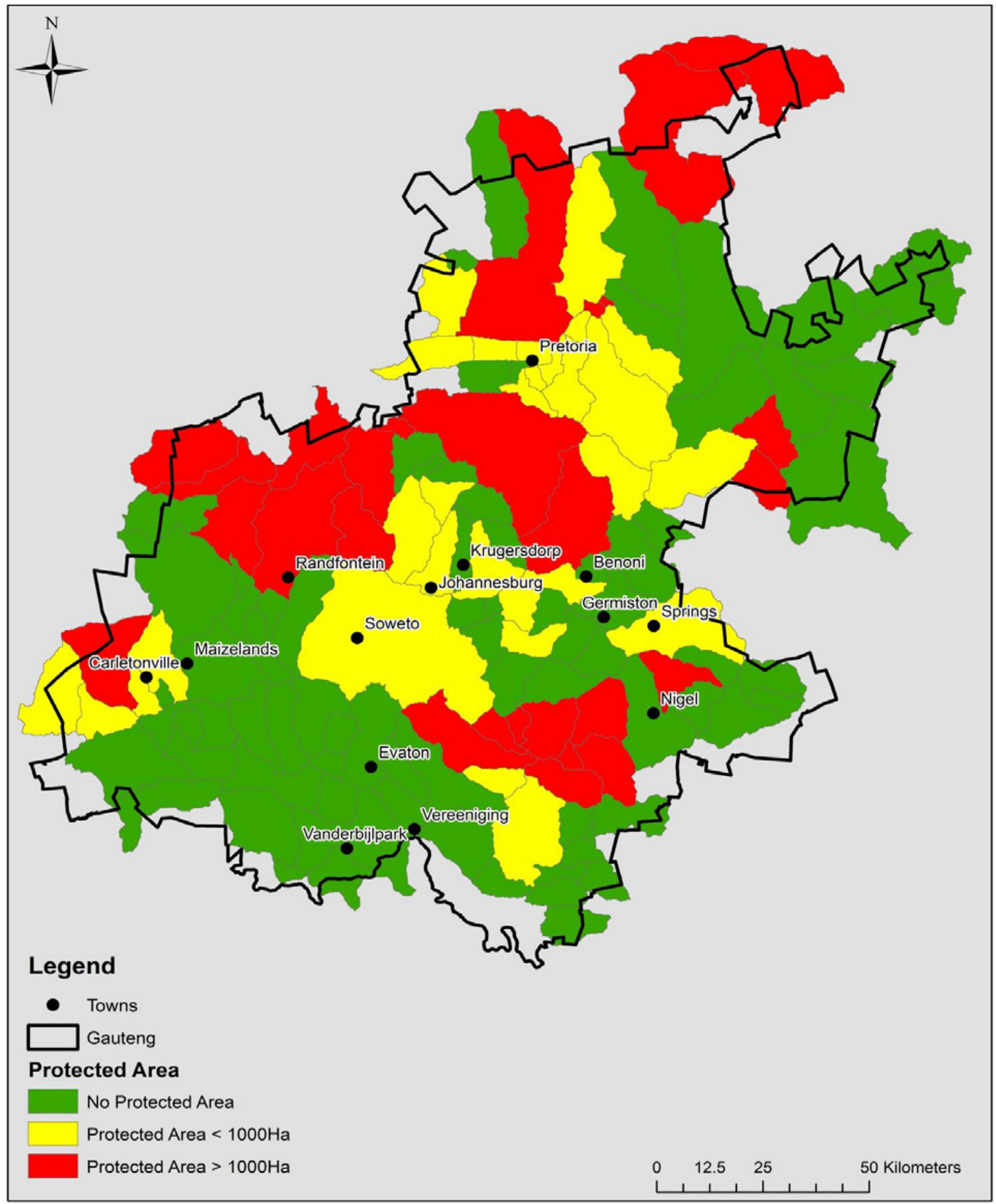

Figure 5

Protected areas per catchment in Gauteng 


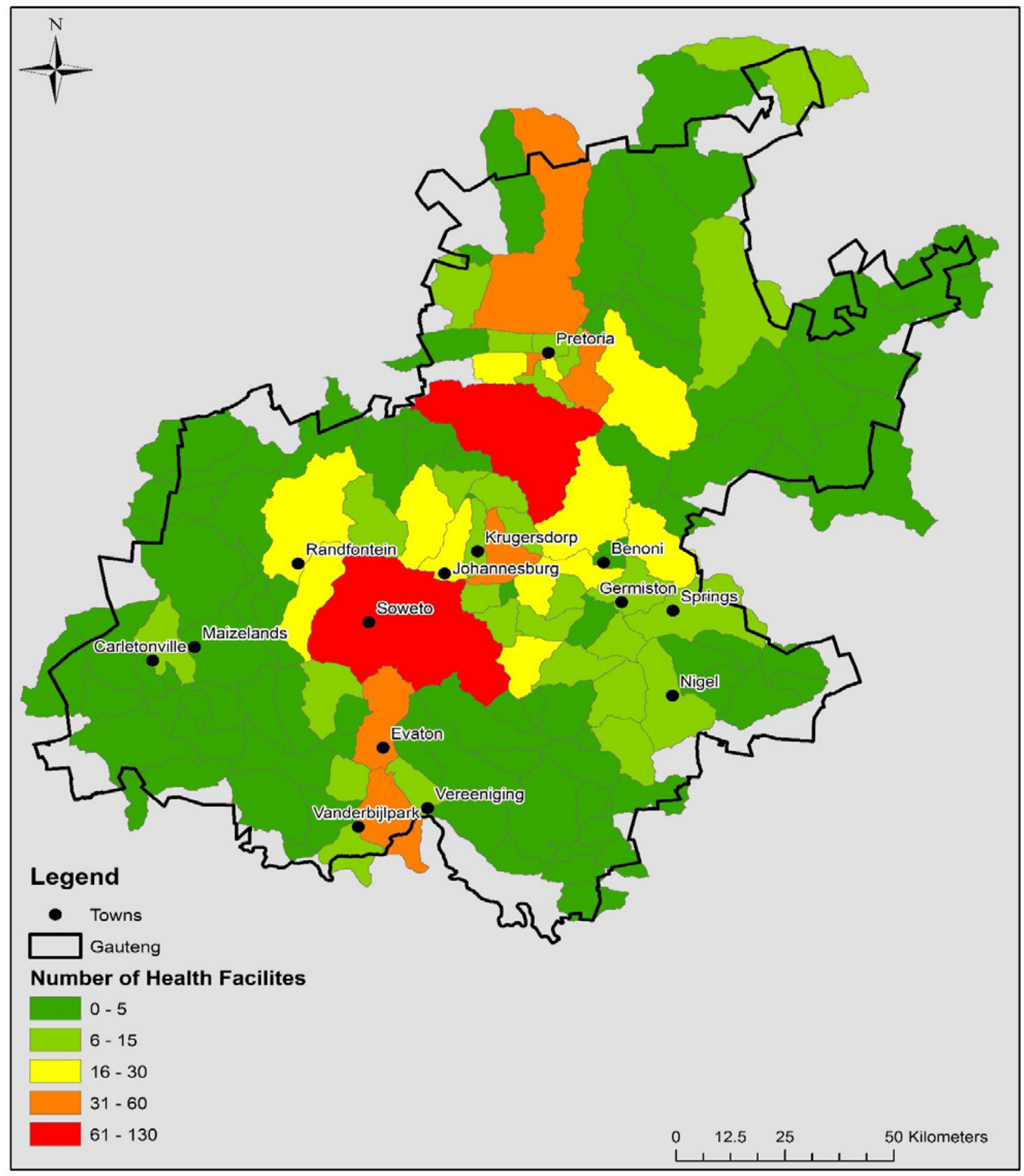

Figure 6

Number of health facilities per catchment in Gauteng 


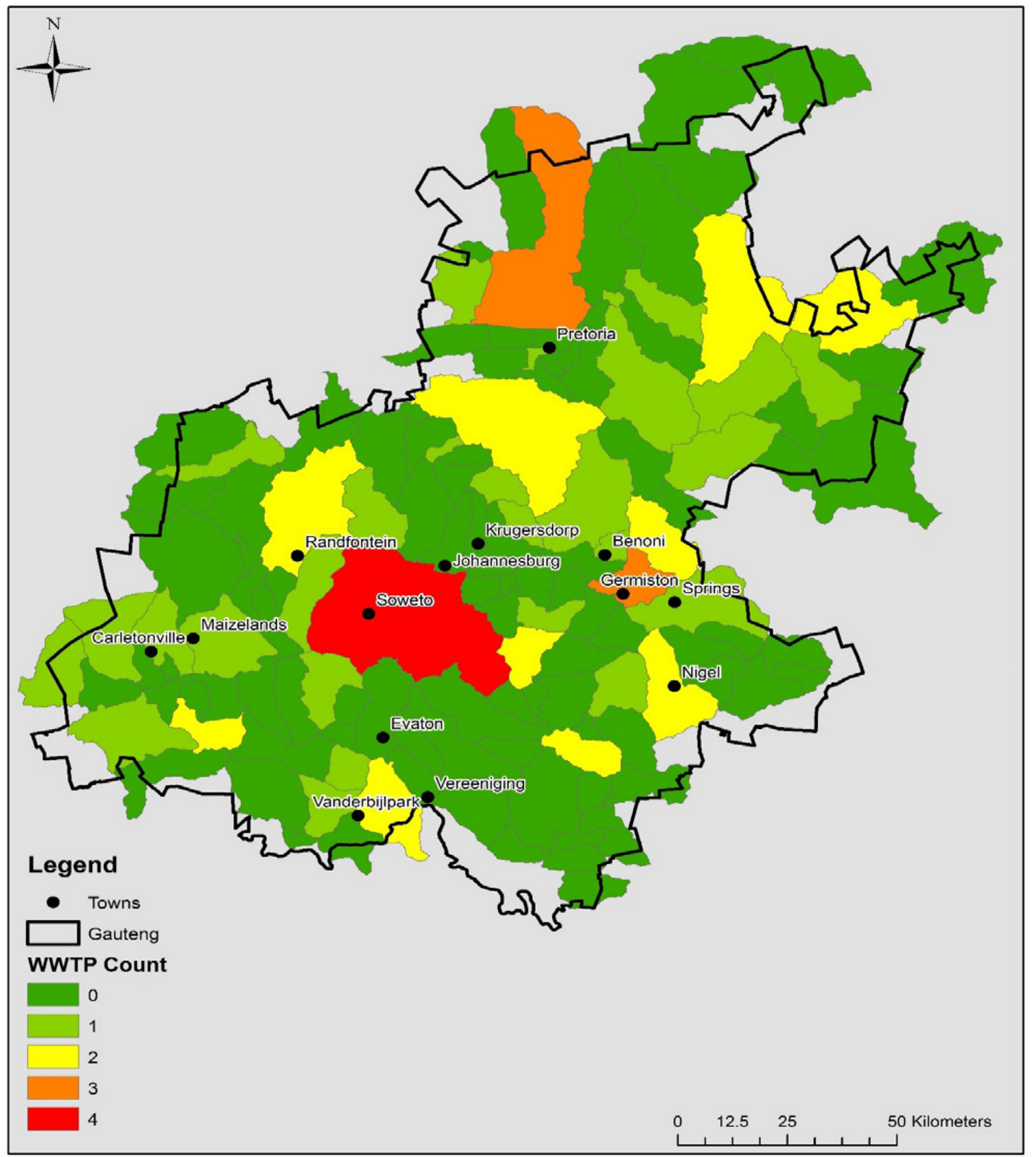

Figure 7

Number of wastewater treatment plants per catchment in Gauteng 


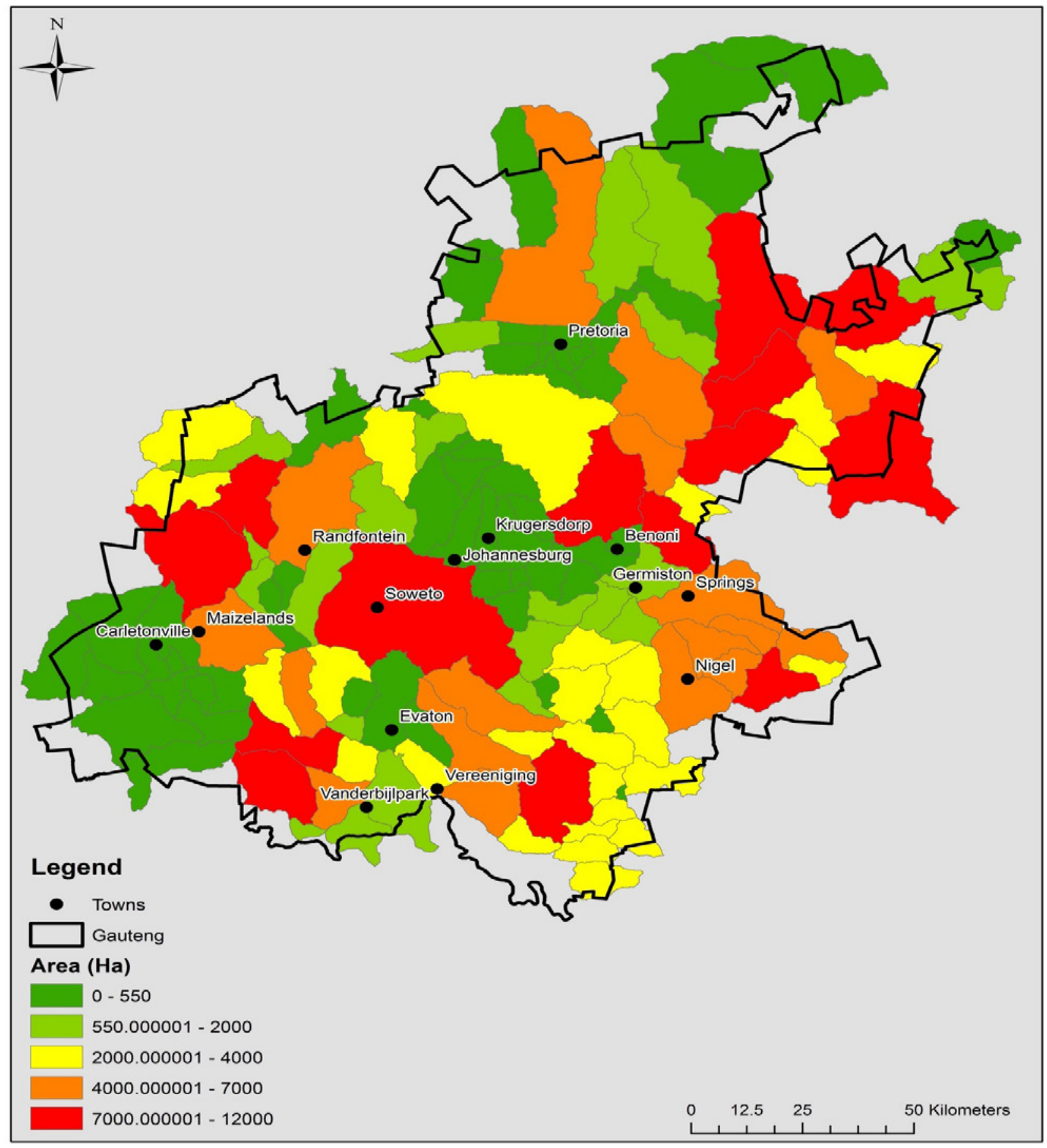

Figure 8

Areas of agriculture per catchment in Gauteng 


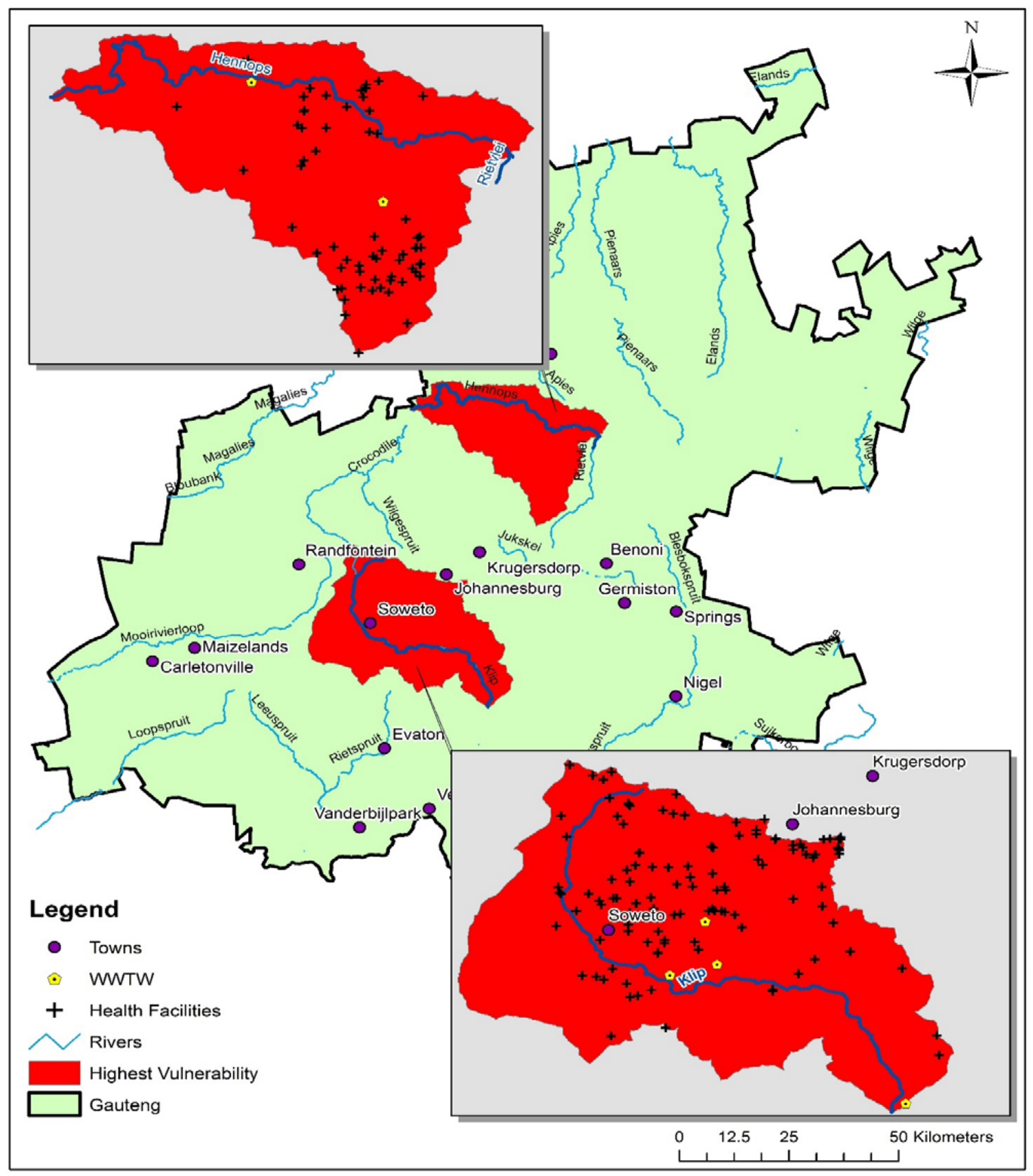

Figure 9

River sections in most vulnerable catchments for anthropogenic substances 


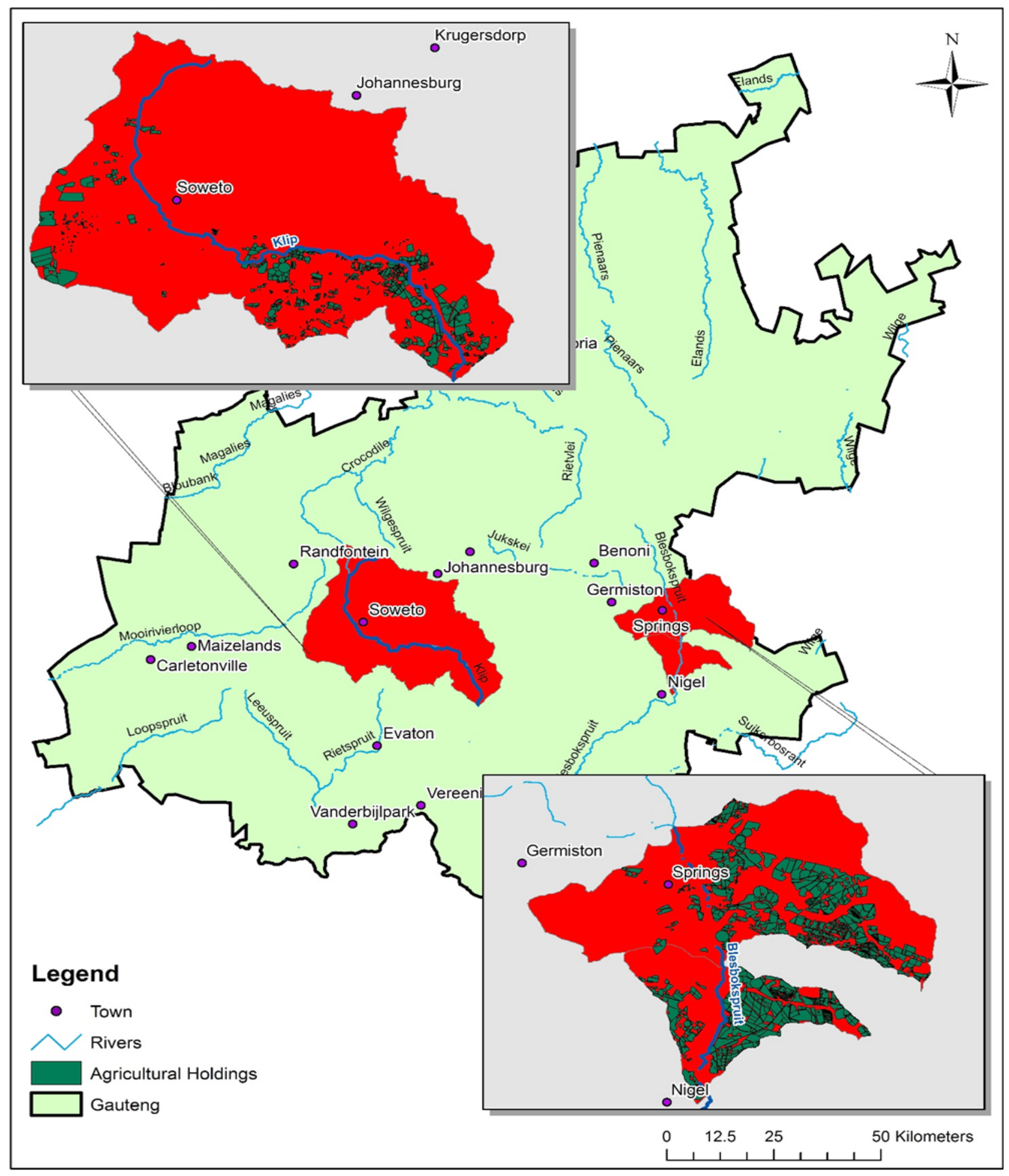

Figure 10

Vulnerable catchment river sections for agricultural substances 


\section{DISCUSSION}

The selection process identified areas along the Klip River as having a high likelihood of containing both anthropogenic ECPs as well as agricultural ECPs. Sections of the Hennops River are likely to contain anthropogenic ECPs. The Blesbokspruit area has a high likelihood of containing agricultural ECPs. The areas identified as being at-risk for anthropogenic substances were densely populated, which greatly elevates the potential exposure risk posed by the ECPs. This was one of the predominant factors that led to the selection of these areas. Both the Hennops River and Klip River areas also featured more than the modus number (2) of WWTWs so their potential for containing ECPs was elevated further.

The areas identified as having the highest potential for agricultural ECP contamination were also areas that featured high population numbers. However, their unique identifier was that the areas also had to feature land that was being actively used for agriculture, which may result in contamination of surface waters with pesticide and animal hormone ECPs, for example.

The geographical locations of risk obtained from this study suggest where the biggest potential problem areas with regards to ECPs (both anthropogenic and agricultural) lie within the province of Gauteng. The identified river sections may serve as a guide to any sampling-driven research that might be conducted in the future. The National Toxicity Monitoring Programme results for the toxicity assessment of the Klip River in 2008 reported that the water quality was good, but the instrument detection limits might not have been sensitive enough to detect the concentrations of pollutants present in the water samples (Jooste et al. 2008). The municipal wards that fall within the identified high-risk areas can use the results of this study to mitigate or avoid potential harm to both ecosystems and the public that are exposed to these ECPs. Educating the public and garnering their support in attempts to minimise the amount of ECPs that end up in water resources could have positive effects in the future.

The identified areas are not the only areas where there is a potential for exposure to ECPs, but represent areas where this is most likely based on the parameters used in this study. Other areas within the province may also be at risk and a thorough ECP monitoring study of surface waters should be conducted throughout Gauteng in order to more accurately determine which areas are most susceptible to harm and where mitigation efforts should be focused.

\section{CONCLUSION}

A holistic, multi-disciplinary approach is recommended to evaluate the potential threats posed by ECPs and also with respect to the removal of these pollutants from a specific environment (Gavrilescu et al. 2014). GIS was successfully used in this study to identify potential sampling sites based on overlaying relevant spatial data layers. The sites identified were located along the Klip River, Hennops River and in the Blesbokspruit area. Sampling of these identified sites will improve our understanding of the status of ECP contamination and will serve to verify whether ECPs may pose a significant threat within these areas.

There are many institutions and individuals who are involved with water monitoring (both sampling and analysis) in the South African context; from researchers and academics, to wastewater treatment works and government departments. The results from this GIS study should serve as a stepping stone for future projects exploring the harmful effects that ECPs can have on both human and environmental health in South Africa. Monitoring performed in the identified at-risk areas should yield valuable insights into exactly how at risk these areas are. Further study and especially monitoring should be completed as this could significantly improve the knowledge base and available literature on ECPs in South African water bodies.

\section{ACKNOWLEDGEMENTS}

Funding from the Water Research Commission (Grant K5/2438), the Photonics Institute of South Africa (Grant PISA-15-DIR-06) and the National Research Foundation (funding grants 90720 and 93394) is gratefully acknowledged.

\section{REFERENCES}

BARNHOORN IEJ, BORNMAN MS, VAN DYK JC, GENTHE B and WAGENAAR GM (2013) Edibility of selected freshwater fish from the Rietvlei dam. WRC Report No. KV281/11. Water Research Commission, Pretoria. ISBN: 978-1-4312-0161-7.

DIAMOND JM, LATIMER HA, MUNKITTRICK KR, THORNTON KW, BARTELL SM and KIDD KA (2011) Prioritizing contaminants of emerging concern for ecological screening assessments. Environ. Toxicol. Chem. 30 (11) 2385-2394. https://doi.org/10.1002/etc.667

FENT K, WESTON A and CAMINADA D (2006) Ecotoxicology of human pharmaceuticals. Aquat. Toxicol. 76 (2) 122-159. https://doi. org/10.1016/j.aquatox.2005.09.009

GAVRILESCU M, DEMNEROVÁ K, AAMAND J, AGATHOS S and FAVA F (2014) Emerging pollutants in the environment: present and future challenges in biomonitoring, ecological risks and bioremediation. New Biotechnol. 32 (1) 147-156.

HAARHOFF J, COETZEE LZ, CERONIO AD, MSAGATI TAM, MAMBA BB, GUMBI N and NKAMBULE TWE (2015) Status quo report on the state of knowledge on persistent organic pollutants and contaminants of emerging concern. Draft Final Report to the Water Research Commission for WRC Project No. K5/2509. Water Research Commission, Pretoria.

JACKSON RB, CARPENTER SR, DAHM CN, MCKNIGHT DM, NAIMAN RJ, POSTEL SL and RUNNING SW (2005) Water in a changing world. Ecol. Appl. 86 (4) 249-250.

JOOSTE S, BOLLMOHR S, THWALA M (2008) National Toxicity Monitoring Programme: Report on Phase 3: Pilot Implementation and Testing of the Design. Report No. N/0000/REQ1008. Resource Quality Services, Department of Water Affairs and Forestry, Pretoria. URL: https://www.dwa.gov.za/iwqs/water_quality/ntmp/ NTMPphase3ReportV2.pdf

LIU Q, ZHOU Q and JIANG G (2014) Nanomaterials for analysis and monitoring of emerging chemical pollutants. Trends Anal. Chem. 58 10-22. https://doi.org/10.1016/j.trac.2014.02.014

NCUBE E, VOYI K and PREEZ H (2012) Implementing a protocol for selection and prioritisation of organic contaminants in the drinking water value chain: case study of Rand Water, South Africa. Water SA 38 (4) 487-504. https://doi.org/10.4314/wsa.v38i4.3 